\title{
Digitalizing industry? Labor, technology and work organization: an introduction to the Forum
}

\author{
Valeria Cirillo ${ }^{1}$. . José Molero Zayas ${ }^{2}$
}

Received: 8 July 2019 / Revised: 8 July 2019 / Accepted: 13 July 2019 / Published online: 20 July 2019 (c) Associazione Amici di Economia e Politica Industriale 2019

The approach to the so called "industry 4.0" and, more generally to the process of digitization, is dominated by internal debates about the technological challenges and opportunities that the new technological developments open, as well as in a considerable extent, regarding direct and indirect impacts on employments (both quantitative and qualitative) and labor conditions. ${ }^{1}$ Two kinds of narratives have emerged over the last years. On the one hand, from a firm-level perspective and based on a managerial discourse, digitalization opens up new opportunities to firms. According to this narrative of "emerging opportunities", firms might become agile and smart, reduce waste, encourage the formation of collaborative working systems, and optimize the inter-organizational relations of the so-called 'industrial ecosystems'. As highlighted in Cirillo et al. (2018) this rhetoric is opposed, on the other hand, by a reading that emphasizes the risks that the pervasive digitalization and interconnection of processes entail. Among these risks: the strengthening concentration (of decisional power) without centralisation (of production) (Harrison 1994); the reaffirming of the process of neo-Taylorisation of work through the introduction of micromanagement practices and new forms of proceduralisation (Alvesson and Sveningsson 2003; Kärreman et al. 2002) characterised by systems of pervasive surveillance (Thompson 2003; Zuboff 2015) and unequal distribution of power and information (Choudary 2018).

In this context—as suggested by Briken et al. (2017a)—intellectual skepticism might be appropriate in order to stimulate a discussion: future of work in the digital era is a matter of debate, rather than a consensus, and a matter of political choices rather than a technological necessity (Pfeiffer 2017).

\footnotetext{
1 We use the English word of "labour" instead of "work" as in the Classical Political Economy to refer to the social context in which work is exerted making productive activities useful for capital and for the generation of surplus value. For a deeper discussion on that, see Frayssé (2014).
}

Valeria Cirillo

v.cirillo@inapp.org

1 INAPP-Istituto Nazionale per l'Analisi delle Politiche Pubbliche, Rome, Italy

2 Instituto Complutense de Estudios Internacionales, Universidad Complutense de Madrid, Madrid, Spain 
The idea to set up a Forum on digitalization-titled "Digitalizing industry? Labour, technology and work organization"-stems from the need to provide a critical understanding of the on-going processes of digitization and to debate its social consequences, specifically those related to labour. Indeed, a common narrative is depicting digitization as a "Fourth Industrial Revolution" (among the others, Schwab 2017) enriching the opportunities of human societies. Among the I4.0 promises, there are comprehensive training opportunities, upward mobility of workers, lower prices of goods, increasing demand and creation of employment in automation-producing firms, and, finally yet importantly, digitalization might contribute to solve social problems and help to meet environmental challenges (Mahnkopf 2019). Is this always the case? ${ }^{2}$

This Forum aims to collect several contributions developed over the last couple of years that provide elements of discussion about the on-going process of digitization and its consequences on work organization and re-organization of industries-with a peculiar attention toward the automotive industry which has been at the forefront of the use of industrial robots since the 1970s and in the use of computer-integrated manufacturing since the 1980s (Briken et al. 2017b).

In our opinion, there are several critical dimensions that would be important to take into account in order to get a more comprehensive and valid debate about digitalization processes and eventually to depict possible policy suggestions.

First, as Cetrulo and Nuvolari-in this Forum - highlight, the adoption of a specific technology within firms is not neutral neither deterministic, but it depends on the complex interaction of knowledge and dynamic capabilities (Zollo and Winter 2002) and on the distribution of power between capital and labor (Braverman 1974). Until now, the academic and non-academic debate has mainly focused on the potential employment "displacement" aspects of new technologies featuring the US American public discourse on jobless growth and destruction of jobs affecting those performing routinary tasks susceptible to be replaced. However, the concern on the impact on employment of technologies is not new (Freeman and Soete 1985) and it comes to the front even in the current debate on the introduction of digital innovation in manufacturing and service industries, while a deep understanding of work organization is lacking and should involve several aspects to deal with. An investigation on the current and future change of labor, work organization and institutions involved in this process has not been entirely carried out. The paper by Moro, Rinaldini, Staccioli and Virgillito in this Forum and the one by Tubaro and Casilli discuss about quality of work related to the use of digital tools, on the one side; and work reorganization on a global scale through the fragmentation of production processes

\footnotetext{
2 The proposal of a Forum draws inspiration from the conferences held in May 2018 in Sapienza University of Rome, Department of Economics, and Sant'Anna School of Advanced Studies, Institute of Economics in Pisa. Both events provided an eclectic perspective to the topic of Industry 4.0 and more general digitalization, collecting interdisciplinary contributions from sociology to economic history and industrial economics. We are especially grateful to Armanda Cetrulo and Angelo Moro who organized the workshop in Sant'Anna School of Advanced Studies and to Mario Pianta for the organization of the Roundtable on Digitalization in Sapienza University of Rome. Their support has been crucial for the development of this Forum.
} 
in micro-tasks, on the other side. Both papers highlight an increasing workers' control stemming from a pervasive use of digitalness.

As a second critical dimension taken into account in this Forum, we question the common narrative of a technological change as a deterministic and neutral process, claiming instead its social and political dimension (Noble 2017). If a non-deterministic approach prevails, a room for opening up a general discussion on modes of production, output and value distribution emerges - as Nuvolari and Cetrulo in this Forum acknowledge. From this point of view, it is worth to understand the specificity of the European industrial structure in which the political design of I4.0 and, more generally, digitalization takes place. Europe as a whole has lost positions as far as the participation in the world industrial production (Pianta et al. 2016; Radosevic 2016; Mira-Godinho and Paes Mamede 2016). This phenomenon has been accelerated in the years after the starting of the world crisis in 2007-2008, while Asian countries have gained substantially in the las decades. Both North America and Europe have decreased but it has been much more intensive in the case of European economies, although with a high degree of heterogeneity among countries. All statistics show how Germany to a considerable extent has maintained its position, particularly if one takes into account the evolution of some "satellite" countries among which Poland occupies a central role (Pianta et al. 2016). More generally, we can assert there exist deep asymmetries between European regions: a Germancore integrated by the German Cluster, the UK and the Nordic countries versus a European periphery in which we can incorporate Portugal, Greece, Italy, Spain and Ireland and a third cluster including Central and Eastern economies. This heterogeneity has to do with a number of economic parameters (i.e. per capita income, fiscal deficits, external debts, rates of unemployment) and industrial structural bases (importance of technological advanced sectors, average size of firms, position of domestic manufacturing companies vis-à-vis global value chains). Although the literature about Industry 4.0 and digitalization has devoted little attention to the former aspects, in our opinion it is clear they have to play a more relevant role in the analysis and policy implication of the current and future situation of Europe. From this point of view, the design of Industry 4.0 might represent a political strategy-more German-to preserve German manufacturing structure in order to put resources on the floor to sustain German industrial apparatus (Pfeiffer 2017). The role of socioeconomic factors as determinants of adoption of I4.0 technologies is at the core of Strohmaier, Schuetz and Vannuccini's contribution in this Forum. They deeply analyze heterogeneities across countries highlighting the difficulties to prescribe a one-fits-all strategy. The role of industrial policy is discussed in Braña and Myro's contributions in this Forum.

As a third critical dimension, we do not take for granted that Industry 4.0 constitutes a novel paradigm of production. How much digital transformation can be assimilated to a "fourth industrial revolution" is still a matter of debate. On the one hand, some authors are critical of the "revolutionary" claims of this transition questioning that I4.0 can constitute a potential 'Fourth Industrial Revolution' and they point out that this transformation characterized by a blurring of the distinctions between physical, digital and biological spheres is a long term process dating back in the last 90s (Castells 1996; Soete 2018). On the other hand, aspects of 
discontinuities of the current phase of digital transformations mainly relate to the rising of a new business model based on market power concentration. The decreasing marginal costs of production of goods and services and the increasing importance of intangible component of capital (Haskel and Westlake 2017) facilitate the generation of "rents" and the insurgence of so-called "winner-take-all" dynamics in industrial organizations (Guellec and Paunov 2017). Continuity versus discontinuities of the current technological phase is at the core of three contributions in this Forum: the ones by Cetrulo and Nuvolari, Marengo, and Pardi.

Indeed, setting aside the discussion about the disruptive character of this new wave or whether we have a new technological paradigm, we are facing an important profound technological change in presence of deep asymmetries among European countries in terms of industrial structures and innovation strategies. The intraEuropean situation is far from being homogeneous. According to the European Innovation Scoreboard 2019, at least two clusters of countries coexist in Europe defining a pattern of dualism: the "innovation leaders" group-Denmark, Finland, the Netherlands and Sweden-and the "strong innovators"-Austria, Belgium, Estonia, France, Germany, Ireland, Luxemburg and the UK-versus the so-called "moderate innovators" group including all southern countries plus several former socialist countries. In this context of high heterogeneities and asymmetries, different countries have been approving plans of investment in order to spur innovation within emerging sectors and in order to provide support and alternative prospects of development for the potentially most affected sectors. However, their outlines are still blurred and confused, because of the complexity of the process and the simultaneous contribution of several factors. A deep reasoning on the new technologies and on the role of labor relations and industrial policy is substantially missing. For instance, trade unions are not involved in the decision phase of technology adoption at the plant level (Cirillo et al. 2019).

Given this scenario, the contributions integrating this Forum take up the challenge to open the debate, unravelling the narrative of a straightforward digitalization process in act and shed some lights on the potential bottlenecks of a "digital revolution". Departing from a technological determinism, they offer interesting reflections on digitalization and its consequences, providing interesting insights on how technologies might shape job contents, work organization and international division of labor.

The article by Marengo discusses two alternative views concerning the occupational and distributional consequences of the current process of digitization. Marengo counterposes two different views. One more optimistic-claiming that we are currently in a transition phase leading in the long run to a positive balance between lost and created jobs-and one more pessimistic according to which the economic characteristics of the technologies in the current industrial revolution are likely to have a negative impact on employment and on social equality. Marengo - taking the side of those arguing for a pessimistic view-highlights that the underlying "microeconomic features" of the new technologies—cost structure of digital technologies, high concentration, de-linking of production and consumption in many services-differ from the previous industrial revolutions. Therefore, some of the virtuous circles operating in the past might not work leading to serious 
societal challenges. Among these, the emergence of a global ploretariat exerting a downward pressure on wages for low skill jobs. This process is part of the global extensions of digital markets reshaping an international process of division of work between workers in the core countries - the "Global North"-and workers located in the periphery. That is exactly the issue discussed by Tubaro and Casilli in relation to micro-work in the automotive industry, one of the largest clients of digital datarelated micro-working services for the development of autonomous and connected cars. Taking advantage of a detailed inventory of micro-working platforms based in France but outsourcing work to providers overseas and international platforms having operations in France, the authors select a sample of 11 platforms that have an explicit AI offer based on the use of micro-work. By means of primary (in-depth interviews with platform workers, platform operators and clients) and secondary data (analysis of information from websites, communication packages, press articles, etc.), the authors analyze which type of tasks autonomous vehicle producers outsource to micro-workers and require from them. Tubaro and Casilli reflect on the implications in terms of international division of labour in the global factory of micro-work which is not bound to disappear with the development of AI solutionsthey argue - but instead represents a structural feature of this reorganization of work where Business Process Automation (BPA) is in fact Business Process Outsourcing (BPO). The development and functioning of AI which is at the core of digitization is based on the work of micro-tasks' workers. We should be concerned-Tubaro and Casilli argue-about the conditions under which these workers operate, the remuneration they get and the future perspectives they have. Indeed, focusing on the quality of work, the article by Moro, Rinaldini, Staccioli and Virgillito aims to reflect on digital control as a feature of the digitization process involving human work. The authors focus on the relationship between technologies and forms of control inside organizations by means of a field research work involving seven firms located in the Italian Motor Valley where Industry 4.0 technologies have been implemented. The use of technological artefacts to increase the possibility of control is not new in the history of capitalism - they argue. By adopting the distinction made by Orlikowski (1991) in personal, bureaucratic and social forms of control, the authors highlight that the implementation of I4.0 technology is increasing the room of control over the work inside organizations. The possibility of gathering large amount of information such as workers' performance data allows the usage of big-data analytics as a mean of control, not simply over the production process, but over workers- the authors argue. Indeed, this opens the venue for workers' control, i.e. to track individual productivity, or for disciplinary purposes, in one word posing threats to workers' autonomy and leading to a pervasive surveillance as foreseen by Zuboff (2015)'s "surveillance capitalism" or toward a "digital despotism" à la Pfeiffer. In this context, the authors argue that the role of trade unions as other forms of workers' representation is pivotal in shaping future trends towards humanizing and democratizing workthey conclude.

Is this process of digitization uniform across countries? Or is it strongly shaped by heterogeneous socio-economic patterns? The link between digitization intended as the conversion of information from analog to digital with respect to socioeconomic features is at the core of Strohmaier, Schuetz and Vannuccini's contribution. 
Focusing on the socioeconomic transformations related to digitalization, the authors analyse the impact of digitalization on overall socioeconomic development and, how similar/different are countries in terms of absorption of technological changes related to digitalization and to Industry 4.0. From this perspective, the authors propose a novel indicator intended to capture the impact of digitalization on the interdependent structural components of socioeconomic systems operationalized in several building blocks: technology, facilitating structure, environment, and policy structure. By collecting data on capital, managerial and financial organization of the firm, location and concentration of industries, organization of labour and production facilities, infrastructure, financial markets and instruments, educational and research institutions, the authors perform a network analysis and a structural decomposition with the specific aim to understand how digitalization contributes to shape the socioeconomic system. They detect two aspects typically associated with the digital transformation such as the reorganization of work and the relative increase of highskilled labour mainly relevant in Western countries.

Focusing on the automotive industry that should be at the forefront of the socalled "Fourth Industrial Revolution", Pardi debates about the concept of digital manufacturing reflecting on its historical roots. He argues that the previous attempts to automate final assembly failed because human base teamwork has proved more flexible and efficient in dealing with complex and evolving assembly processes. Pardi underlines that the two main drivers that have spurred previous automation waves in the automotive sector appear to be absent in the current phase such as the productivity and quality problems affecting carmakers in the 1980s, and the labor shortage and workers' discontent affecting Japanese automotive industry in the 1990s. However, it seems that Industry 4.0 is spurring the vision of automation for the sake of automation-declared Pardi. According to the author, Industry 4.0 resembles more to a political project put on the ground by consortiums of dominant national industries to address economic problems exacerbated by the 2008-2009 economic crisis such as the decline of sales in industrial equipment for German firms facing a higher international competition. Consequences of automation on employment and work organization are more subtle than the narrative on Industry 4.0 would depict-he wrote. As suggested by Moro et al. in this Forum, also Pardi envisages major changes on work organization going through deskilling of some tasks and increased control of workers through data collection and analysis. Deskilling, segmentation and polarization of skills related to category of workers more linked to the introduction of digital technologies might take place in a context of increasing flexibilisation and intensification of work.

Still adopting an historical perspective on previous technological revolution, Cetrulo and Nuvolari discuss industry 4.0 showing a pattern of continuity with respect to past technological trends. The authors clearly argue that the development in Artificial Intelligence, communication and robotics at the core of the so-called "fourth industrial revolution" appears a natural prolongation of the ICT macro-trajectories. By focusing on two major applications of internet of things at the workplace, Cetrulo and Nuvolari explore how and to which extent it is appropriate to regard the current technological trends in ICT as a structural discontinuity. They focus, as Moro, Rinaldini, Staccioli and Virgillito do, on a peculiar aspect of the 
current adoption of technologies in the workplace-specifically Radio Frequency Identification system (RFID) and wearable technologies (WSN), which according to the authors might reach its peak in terms of efficacy and pervasiveness. They emphasize how the exertion of control over workers constitutes an element of continuity in management practices and management systems. Finally, the authors claim for a proper mix of economic and social policies to avoid increasing income inequality, which is the main message stemming from Myro's contribution focusing on the role that a proper industrial policy should have in a context of ubiquitous connectivity and massive computation.

Myro strongly claims for a vigorous industrial policy built on renewed bases. As previous industrial revolutions, Myro highlights that the actual phase of digitalization is characterized by the emergence of giant technological companies, by the extension of new production methods and by uncertainty hindering productive investments. Given that, the author raises two questions. The first one is whether in this new industrial revolution manufacturing industry will play the central role that played in the previous ones. If so, Myro argues to what extent the policy directed towards manufacturing will be sufficient or instead it should become a more proactive strategy. He reflects on which type of industrial policy would be needed (innovation-driven, export-oriented, etc.) and which features should characterize its implementation.

On the same ground, departing form a technological determinism and considering technologies as part of a social relationship, production systems and specific mode of accumulation and regulation, Braña criticizes the conceptualization of the current digitization as a fourth industrial revolution. He stresses the continuity of the current phase with respect to the information and communication technologies. By taking advantage of the Freeman and Louça (2001)'s conceptualization of long waves, Braña considers digitalization of the economy more as an uncertain transition from one phase to another of the same techno-economic paradigm than as a new industrial revolution. By means of a revision of secondary sources (such as scientific reports, technical figures, articles, etc.), Braña reflects on employment dynamics related to digitalization such as polarization of jobs and automation potentially leading to loss of jobs. A special focus is deserved to job quality and working conditions: digitization may facilitate the breakdown and subcontracting of an increasing number of tasks. Subcontracting and outsourcing can result in less favorable conditions of employment due to instability in contractual arrangements, low wages and working hours. Is there an industrial policy feasible? This is the main question at the core of Braña's reflection. He discusses some options for industrial policies concluding with some skepticism about the real possibilities of implementing major changes due to the prevailing of a core-periphery dynamics in Europe and an unequal distribution of power among key political actors.

To conclude, we claim for a profound debate that might take insights - as we intended to do in this Forum-from different perspectives and field of studies. Promoting an interdisciplinary approach to detect and discuss the social consequences emerging from the use of the new digital technologies in many aspects of the industrial production and distribution of good and services would be fundamental. We have insisted in the necessity of an intellectual skepticism that neither admits the 
technological determinism of the new technologies (technology as a social relationship) nor tries to deny the new qualitative elements brought during the last years. Moreover, even if the debate suggested is concentrated on the industrial sectors, we must not forget that the process might spread to all the economy, although at different speeds. Particularly important is to recognize that the boundaries from industry to services are increasingly blurred. Similarly, we should insist on the necessity to not concentrate the attention just on few sectors in which the digitization process is more extended (i.e. automotive industry): particularly for Southern European countries it is crucial to analyse the processes on the so called "traditional sectors" (i.e. food and beverages; food and leather or even tourism). Are these sectors excluded from the I4.0 "revolution"? In that case, we should claim for a new industrial policy for the periphery of Europe where these sectors are still relevant. Indeed it is crucial to take into account the formerly mentioned differences in industrial and economic structures across Europe to avoid the risk that specific program such as the one envisaged by I4.0 appears to be too country-specific, aimed to sustain the competitiveness of those countries already equipped by high-tech production structures.

\section{References}

Alvesson, M., \& Sveningsson, S. (2003). Good visions, bad micro-management and ugly ambiguity: Contradictions of (non-) leadership in a knowledge-intensive organization. Organization Studies, 24(6), 961-988.

Braverman, H. (1974). Labor and monopoly capital. New York: Monthly Review.

Briken, K., Chillas, S., \& Krzywdzinski, M. (2017a). The new digital workplace: How new technologies revolutionise work. Critical Perspectives on Work and Employment. Basingstoke: Palgrave McMillan. ISBN 9781137610133, 1137610131.

Briken, K., Chillas, S., Krzywdzinski, M., \& Marks, A. (2017b). Labour process theory and the new digital workplace. In The new digital workplace: How new technologies revolutionise work. Critical Perspectives on Work and Employment. Basingstoke: Palgrave McMillan. ISBN 9781137610133, 1137610131.

Castells, M. (1996). The rise of the network society. Oxford: Blackwell.

Choudary, S. P. (2018) The architecture of digital labour platforms: Policy recommendations on platform design for worker well-being. ILO Future of work Research Paper Series, ISBN 978-92-2-030770-0.

Cirillo, V., Rinaldini, M., Staccioli, J., \& Virgillito, M. E. (2018). Workers' intervention authority in Italian 4.0 factories: Autonomy and discretion, LEM Papers Series 2018/13, Laboratory of Economics and Management (LEM), Sant'Anna School of Advanced Studies, Pisa, Italy.

Cirillo, V., Rinaldini, M., Staccioli, J., \& Virgillito, M. E. (2019). Trade unions responses to Industry 4.0: From corporatism to old and new dualistic tendencies, Forthcoming, LEM Papers Series, Laboratory of Economics and Management (LEM), Sant'Anna School of Advanced Studies, Pisa, Italy.

Frayssé, O. (2014). Work and labour as metonymy and metaphor. TripleC: Communication, Capitalism \& Critique. Open Access Journal for a Global Sustainable Information Society, 12(2), 468-485.

Freeman, C., \& Louca, F. (2001). As time goes by: From the industrial revolutions to the information revolution. Oxford: Oxford University Press.

Freeman, C., \& Soete, L. L. G. (1985). Information technology and employment: An assessment. University of Sussex.

Guellec, D., \& Paunov, C. (2017). Digital innovation and the distribution of income (No. w23987). National Bureau of Economic Research.

Harrison, B. (1994). Lean and mean: The changing landscape of corporate power in the age of flexibility. New York: Basic Books. https://doi.org/10.2307/2524930. 
Haskel, J., \& Westlake, S. (2017). Capitalism without capital: The rise of the intangible economy. Princeton: Princeton University Press.

Kärreman, D., Sveningsson, S., \& Alvesson, M. (2002). The return of the machine bureaucracy? Management control in the work settings of professionals. International Studies of Management \& Organization, 32(2), 70-92.

Mahnkopf, B. (2019) The '4th wave of industrial revolution'-a promise blind to social consequences, power and ecological impact in the era of 'digital capitalism'. EuroMemo Group. Discussion Paper No. 01/2019. ISSN 2523-9163.

Mira-Godinho, M., \& Paes Mamede, R. (2016). What can we expect from low and medium to low tech specialization in the EU southern belt? Paper presented to the workshop on innovation and competitivity in mature sectors. Madrid: Fundación Ramón Areces.

Noble, D. (2017). Forces of production: A social history of industrial automation. UK: Routledge.

Orlikowski, W. J. (1991). Integrated information environment or matrix of control? The contradictory implications of information technology. Accounting, Management and Information Technologies, 1(1), 9-42. https://doi.org/10.1016/0959-8022(91)90011-3.

Pianta, M., Lucchese, M., \& Nascia, L. (2016). What is to be produced. The making of a new industrial policy in Europe. Brussels: Rosa Luxemburg Stiftung.

Radosevic, S. (2016). Industrial and technological upgrading of Central and East European economies. Paper presented to the workshop on Innovation and Competitivity in mature sectors. Madrid: Fundación Ramón Areces.

Schwab, K. (2017). The fourth industrial revolution. World Economic Forum. Crown Publishing Group New York. ISBN-13: 978-1-944835-01-9.

Soete, L. (2018). Destructive creation. Explaining the productivity paradox in the digital age. In M. Neufeind, J. O'Reilly, F. Ranft (Eds.), Work in the digital age: Challenges of the fourth industrial revolution. London: Rowman and Littlefield.

Thompson, P. (2003). Fantasy Island: A labour process critique of the 'age of surveillance'. Surveillance \& Society, 1(2), 138-151.

Pfeiffer, S. (2017) Industrie 4.0 in the Making-discourse patterns and the rise of digital despotism. In K. Briken, S. Chillas, M. Krzywdzinski (Eds.), The new digital workplace: How new technologies revolutionise work (pp. 21-41). UK: Macmillan International Higher Education.

Zollo, M., \& Winter, S. G. (2002). Deliberate learning and the evolution of dynamic capabilities. Organization Science, 13(3), 339-351.

Zuboff, S. (2015). Big other: Surveillance capitalism and the prospects of an information civilization. Journal of Information Technology, 30(1), 75-89.

Publisher's Note Springer Nature remains neutral with regard to jurisdictional claims in published maps and institutional affiliations. 